\title{
Prevention of post-ERCP pancreatitis: where are we now?
}

\section{Giovanna Sheiybani; Benjamin Colleypriest*}

Royal United Hospital Bath NHS Trust, UK

\section{*Corresponding Author(s): Benjamin Colleypriest}

Royal United Hospital Bath NHS Trust, UK

Email: bcolleypriest@nhs.net

Received: Apr 08, 2018

Accepted: Jun 15, 2018

Published Online: Jun 22, 2018

Journal: Annals of Gastroenterology and the Digestive System Publisher: MedDocs Publishers LLC

Online edition: http://meddocsonline.org/

Copyright: (C) Colleypriest B (2018). This Article is distributed under the terms of Creative Commons Attribution 4.0 International License

Keywords: ERCP; Pancreatitis; NSAIDs; Pancreatic stents

\section{Introduction}

Endoscopic Retrograde Cholangio Pancreaticography (ERCP) is used worldwide and is a first line therapeutic procedure to manage a range of pancreatic and biliary disorders. As with many endoscopic procedures, ERCP has potential complications associated with it, of which Post-ERCP Pancreatitis (PEP) is the most common. The reported incidence of PEP is up to $10 \%$ in unselected cases and carries significant morbidity [1]. Risk factors for PEP include female gender, sphincter of oddi dysfunction and a prior history of PEP [2]. Table 1 summaries the main risk factors for PEP.

ERCP is practised as a therapeutic test in the vast majority of situations, with MRCP and EUS providing less invasive diagnostic modalities. It is vital to limit the occurrence of PEP and a variety of measurers have been employed. Non-Steroidal AntiInflammatory Drugs (NSAIDs), prophylactic pancreatic stenting

\begin{abstract}
Endoscopic Retrograde Cholangio-Pancreatography (ERCP) is a first-line therapeutic investigation to manage a wide range of pancreatic and biliary disorders. Post-ERCP pancreatitis is a well-recognised common complication with significant morbidity and mortality. There are a large number of interventions than have been employed to decrease this risk. In this mini-review, we summarise measures that can be used to decrease the risk of post ERCP pancreatitis. Procedural factors that will be explored include patient selection, cannulation time, pancreatic duct injection of contrast, pre-cut sphincterotomy and guide-wire assisted cannulation. Therapeutic interventions that will be covered include rectal NSAIDs, aggressive pre-hydration of Ringer's lactate and prophylactic pancreatic stents.
\end{abstract}

and specific procedural-related factors are the best proven interventions to decrease the incidence of PEP. This review will explore these various interventions and summarise the available evidence in relation to their effectiveness in reducing PEP in an evolving field.

\section{NSAIDs}

Multiple studies have shown that there is a clear benefit of using rectal NSAIDs to reduce the risk of PEP. Sajid et al. [3] performed a systematic review of thirteen randomised controlled trials and demonstrated that rectal NSAIDs significantly reduced the risk of PEP in all-risk patients by $57 \%$ (OR 0.43). This is echoed in a meta-analysis performed by Yaghoobi et al. [4] (OR 0.49) and Sun et al. [5] (RR 0.45). However, all the evidence is not positive: $A$ large randomised controlled trial by Levenick et al. [6] suggested that the incidence of PEP was not reduced by rectal NSAIDs in average and low-risk patients, adding to the 
controversy. Subsequent meta-analyses have looked at studies performed in low- to average-risk of PEP have shown a benefit $[7,8]$ and this may mean that the Levenick study could be an outlier. Another smaller study performed by Rainio et al. in 2017 [9] revealed that diclofenac had no beneficial effect in reducing PEP in unselected patients, but the authors do suggest this could be due to their low incidence of PEP. The evidence in the UK has been sparse, with only one RCT in 2003 demonstrating its benefit [10]. A more recent retrospective observational study has demonstrated benefit in a district general hospital and has provided further evidence of its benefit [11]. Phospholipase A2 has been implicated in the pathogenesis of acute pancreatitis and found to be significantly elevated in severe pancreatitis [12]. Both indomethacin and diclofenac are potent inhibitors of phospholipase A2 suggesting a mechanistic rationale for its use [13]. An observational study performed in the UK revealed that those patients already on NSAIDs for other medical conditions may have a protective effect on developing complications related to acute pancreatitis [14], although there has been no study to date looking at a direct relationship between using NSAIDs in the acute setting and the prevention of complications related to acute pancreatitis. There have been very few studies examining the efficacy of NSAIDS in reducing the severity of established PEP. A meta-analysis performed by Elmunzer et al in 2008 showed that rectal NSAIDs reduces the severity [15] but this was not supported by a more recent meta-analysis performed by Li et al. [16].

There have been limited studies comparing different NSAIDs, with most of the meta-analyses comparing all NSAIDs with placebo, where a clear benefit has been demonstrated. Mohammed Alizadeh et al performed a small randomised study of 372 patients and found that rectal indomethacin and diclofenac were more effective than naproxen [17]. Sajidetal'smeta-analysis suggests that diclofenac is more effective than indomethacin [3], with a 55\% reduction in PEP with diclofenac compared to $41 \%$ with indomethacin.

Despite the negative studies, the low cost of NSAIDs, ease of use, the growing body of evidence and safety profile contribute to the recommendation by the American Society of Gastrointestinal Endoscopy (ASGE) and the European Society of Gastrointestinal Endoscopy (ESGE) that rectal NSAIDs should be given peri-procedure in all without contraindication.

\section{Procedural factors}

There are a number of procedural factors that have been linked to the development of PEP but randomised trials are difficult because of confounding factors. Funatsu et al. [18] performed an observational, retrospective analysis of 1334 patient who underwent ERCP over four years (all performed by experienced endoscopists) and found that a higher risk of PEP was likely in those with longer cannulation times (specified as more than fifteen minutes), especially if there is a history of previous PEP. There were limitations to this study, namely the fact it was a single-centre study and not all patient-related risk factors were accounted for, e.g. Sphincter of Oddi dysfunction. Similarly, longer cannulation time is a surrogate marker of a difficult ERCP and not something that can be controlled. Testoni et al. [19] report a prospective multi- centre study from 2010 which reviewed 3635 ERCPs performed in a mixture of low- and high-volume centres in an attempt to determine if volume was related to complications. Interestingly, the rates of PEP did not differ significantly between the types of centre nor between expert and non-expert operators. They identified multiple at- tempts to cannulate the ampulla, pancreatic duct cannulation, injection of contrast into the pancreatic ductal system and pancreatic sphincterotomy as significant associations with PEP. The conclusion was that these are independent risk factors for PEP, regardless of the expertise of the endoscopist, These risk factors are also identified in multiple other studies internationally (e.g. Bailey et al [20]).

Table 2 summaries the variety of procedural techniques that have been assessed in their ability to reduce PEP. Tse et al. [21] performed a meta-analysis in 2012 examining the effects of Guide-Wire (GW) assisted cannulation as opposed to contrastguided. It was found that GW improved the cannulation success rate (RR 1.07) and reduced the need for a pre-cut sphincterotomy (RR 0.75), suggesting both independently reduces the rate of PEP. Tse et al. also found that the $\mathrm{GW}$-assisted technique reduced the rate of inadvertent pancreatic duct manipulation (either contrast injection or cannulation), although this was non-significant (RR 0.88). However, if a pancreatic duct stent was used, the use of GW compared with contrast-assisted did not significantly reduce the rate of PEP (4.8\% v 5.5\%, RR 0.92). Artifonet al [22] performed an RCT of 300 patients to assess the use of GW-assisted cannulation and the results support Tse's meta-analysis (OR 0.43).

Precut sphincterotomy and fistulotomy have been suggested to be linked to increased rates of PEP but it is likely that these are surrogate markers for difficult cannulations and prolonged procedures rather that increasing the rate per se. There is evidence that early use of precut does not increase rates of PEP and some studies have demonstrated that it can significantly reduce the rate of $\mathrm{PEP}$, as demonstrated by a retrospective, comparative study by Ang et al. [23]. In cases of difficult biliary cannulation, the use of precut sphincterotomy in place of persistence of other techniques has been shown to reduce the risk of PEP $[24,25]$.

\section{Prophylactic pancreatic stents}

Use of prophylactic pancreatic stents to reduce PEP has been examined extensively in the literature.

Choudhary et al. [26] performed a meta-analysis of the utility of pancreatic stents in reducing PEP. Despite the heterogeneity in the studies, particularly the size and type of stent, it did show a significant benefit of using stents to reduce PEP (OR 0.22). This has been supported by further meta-analyses performed by Mazeki et al [27] and Singh et al. [28]. An analysis performed by Das et al. [29] found them to be cost-effective in reducing the rates of PEP. It is particularly effective in patients who undergo pancreatic guide-wire cannulation or contrast injection to achieve biliary cannulation. ARCT comparing pancreatic guide wire cannulation with other precut techniques revealed significantly higher rates of PEP [30] in the double guide wire technique. The 2014 ESGE guidelines [31] advocate the restricted use of pancreatic guide wire cannulation for biliary cannulation only in situations where the pancreatic duct is inadvertently cannulated. Pancreatic stenting is useful in those patients with Sphincter of Oddi dysfunction, a known risk factor for PEP, as demonstrated by Saad et al. (OR 4.1) [32]. A large multi-centre trial demonstrated that prophylactic pancreatic stenting in high risk patients may lessen the severity of pancreatitis, although this conclusion was derived from the fact that the majority of patients that did develop PEP were mild [33]. A small retrospective, observational study did show there may be some benefit in reducing PEP by giving rectal NSAIDs if a prophylactic pancre- 
atic stent has failed [34]. A network meta-analysis performed by Akbar et al. [35] suggests that rectal NSAIDS may be superior to pancreatic duct stents to reduce PEP, although it was limited by the small number of studies included. This supports a posthoc analysis performed by Elmunzer et al. [36] which also suggested that those who received rectal NSAIDs alone were at the lowest risk of PEP compared to NSAIDs plus pancreatic stent. Larger, prospective clinical trials comparing these methods are required in order to conclude as to whether one is more effective than the other in reducing PEP.

There are very few studies assessing which calibre of stent is more effective. Lee et al. [37] performed a small study of 101 patients and demonstrated that a $3 \mathrm{~F}$ pancreatic stent in patients with difficult biliary cannulation is effective and safe in patients to reduce PEP. Expert opinion suggests that a long 3-4F or short 5-6F stents may reduce the risk of stent migration, which may cause delayed-onset PEP [38].

\section{Pre-hydration}

There have been few studies examining the effect of intensive fluid hydration to patients undergoing ERCP to prevent PEP. A systematic review performed by Smeets et al. [39] did support the use of aggressive hydration but the majority of studies were small and generally observational, and the authors do highlight that larger studies examining this specific effect were required before guidance could be given. As to the type of fluid that should be given, the American College of Gastroenterology guidelines [1] advocate the use of Ringer's lactate solution based on one small study [40]. A more recent large study performed by Park et al. [41] did show a significant decrease in PEP when patients with aggressive hydration pre-procedure in average to high-risk patients. The evidence based for this is currently limited and more studies are required to demonstrate a benefit of this. There have currently been no head-to-head trials between pre-hydration and NSAIDs and Smeet's meta-analysis note that as none of the studies included NSAIDs, a conclusion regarding any additive effect could not be made.

\section{Conclusion}

(Table 3 summarises the various interventions that have been explored and the guidance associated with the evidence.)

PEP carries a significant morbidity and a mortality. There are multiple cost-effective interventions demonstrated to reduce the risk of PEP including peri procedural NSAIDS and prophylactic pancreatic stenting. Interestingly the combined use does not seem to reduce the risk of PEP further although large blinded studies are awaited. The precise role of pancreatic stents in the prevention of PEP is unclear in the era of NSAIDS but should be considered when the pancreatic duct has been cannulated or contrast injected. It would not seem logical to cannulate a virgin pancreatic duct to place a stent especially if NSAIDS are used. The growing body of evidence, ease of use and safety profile of rectal NSAIDS peri-procedure clearly supports their use unless contraindicated. The type of NSAID and timing of administration requires further studies. Identifying those patients at higher risk of PEP may help to determining which of these interventions should be used or identify a subgroup requiring both NSAIDS and stenting. Rectal NSAIDs and prophylactic pancreatic stenting if the pancreatic duct has been manipulated should be used in all without contraindication. There is limited evidence for aggressive pre-hydration but this has not been proven in subsequent studies. Further studies could focus on the best com- bination of methods to prevent PEP. Case selection for ERCP is beyond the remit of this mini-review but it is clear that the most efficient method of avoiding PEP is not to perform an ERCP and necessity need to be questioned for all procedures.

Tables

Table 1: Risk factors for PEP.

\begin{tabular}{|l|l|}
\hline \multicolumn{1}{|c|}{ Patient-related factors } & \multicolumn{1}{c|}{ Procedure-related factors } \\
\hline Female gender & Difficult cannulation \\
\hline Sphincter of Oddi dysfunction & $\begin{array}{l}\text { Cannulation or injection into the pan- } \\
\text { creatic duct }\end{array}$ \\
\hline Prior history of PEP & Biliary balloon sphincter dilation \\
\hline Younger age & \\
\hline Normal serum bilirubin & \\
\hline
\end{tabular}

Adapted from: Dumonceau JM, Andriulli A, Elmunzer BJ et al. Prophylaxis of post-ERCP pancreatitis: European Society of Gastrointestinal Endoscopy (ESGE) guideline - updated June 2014. Endoscopy. 2014; 46: 799-815.

Table 2: Techniques that could be used to help reduce PEP.

Guide wire-assisted biliary cannulation

Early pre-cut sphincterotomy

Prophylactic pancreatic stents

Short-wire technique

Double-wire technique (if performed with the use of a prophylactic pancreatic stent)

Adapted from: Elmunzer BJ. Reducing the risk of post-endoscopic retrograde cholangiopancreatography pancreatitis. Digestive Endoscopy. 2017; 29: 749-757.

Table 3: Interventions with evidence of reducing PEP.

\begin{tabular}{|l|l|}
\hline \multicolumn{1}{|c|}{ Evidence available } & \multicolumn{1}{c|}{ Limited evidence } \\
\hline Rectal NSAIDS & $\begin{array}{l}\text { Pre-procedural aggressive } \\
\text { hydration }\end{array}$ \\
\hline Prophylatic pancreatic stenting & \\
\hline $\begin{array}{l}\text { Guidewire-asssisted biliary can- } \\
\text { nulation }\end{array}$ & \\
\hline Early pre-cut sphincterotpmy & \\
\hline
\end{tabular}

\section{References}

1. Chandrasekhara V, Khashab MA, Muthusamy R, Acosta RD, Agrawal D, Bruining $\mathrm{DH}$, et al. Adverse events associated with ERCP. Gastrointestinal Endoscopy. 2017; 85: 32-47.

2. Arata S, Takada T, Hirata K, Yoshida M, Mayumi T, Hirota M, et al. Post-ERCP pancreatitis. J Hepatobiliary Pancreat Sci. 2010; 17: 70-78.

3. Sajid MS, Khawaja AH, Sayegh M, Singh KK, Philipose Z. Systematic review and meta-analysis on the prophylactic role of nonsteroidal anti-inflammatory drugs to prevent post-endoscopic retrograde cholangiopancreatography pancreatitis. World J Gastrointest Endosc. 2015; 7: 1341-1349.

4. Yaghoobi M, Rolland S, Waschke KA, McNabb-Baltar J, Martel 
$M$, Bijarchi R, et al. Meta-analysis: Rectal indomethacin for the prevention of post-ERCP pancreatitis. Aliment Pharmacol Ther. 2013; 38: 995-1001.

5. Sun HL, Han B, Zhai HP, Cheng XH, Ma K. Rectal NSAIDs for the prevention of post-ERCP pancreatitis: A meta-analysis of randomised controlled trials. Surgeon. 2014; 12: 141-147.

6. Levenick JM, Gordon SR, Fadden LL, Levy LC, Rockacy MJ, Hyder $\mathrm{SM}$, et al. Rectal indomethacin does not prevent post-ERCP pancreatitis in consecutive patients. Gastroenterology. 2016; 150: 911-917.

7. Shen C, Shi Y, Liang T, Su P. Rectal NSAIDs in the prevention of post-endoscopic retrograde cholangiopancreatography pancreatitis in unselected patients: systematic review and metaanalysis. Dig. Endosc. 2017; 29: 281-290.

8. Patai A, Solymosi N, Mohasci L, Patai ÁV. Indomethacin and diclofenac in the prevention of post-ERCP pancreatitis: A systematic review and meta-analysis of prospective controlled trials. Gastro intest Endosc. 2017: 85; 1144-1156.

9. Rainio M, Lindstrom O, Udd M, Louhimo J, Kylänpää L. Diclofenac does not reduce the risk of post-endoscopic retrograde cholangiopancreatography pancreatitis in low-risk units. J Gastrointest Surg. 2017; 21: 1270.

10. Murray B, Carter R, Imrie C, Evans S, O'Suilleabhain C. Diclofenac reduces the incidence of acute pancreatitis after endoscopic retrograde cholangiopancreatography. Gastroenterology. 2003; 124: 1786-1791.

11. Sheiybani G, Brydon P, Toolan M, Linehan J, Farrant M, Colleypriest $B$. Does rectal diclofenac reduce post-ERCP pancreatitis? A district general hospital experience. Frontline Gastroenterology. 2018; 9: 73-77.

12. Puolakkainen P, Valtonen V, Paananen A, Schröder T. C-reactive protein (CRP) and serum phospholipase $A 2$ in the assessment of the severity of acute pancreatitis. Gut. 1987; 28: 764-771.

13. Makela A, Kuusi T, Schroder T. Inhibition of serum phospholipase $A 2$ in acute pancreatitis by pharmacological agents in vitro. Scand J Clin Lab Invest. 1997; 57: 401-407.

14. Baxter KA, Pucher PH, Berry DP, Elberm H, Abu-Hilal M, Marangoni $\mathrm{G}$, et al. The effect of non-steroidal anti-inflammatory drugs on severity of acute pancreatitis and pancreatic necrosis. The Annals of the Royal College of Surgeons of England. 2018; 100: 199-202.

15. Elmunzer BJ, Waljee AK, Elta GH, Taylor JR, Fehmi SM, Higgins PD. A meta-analysis of rectal NSAIDs in the prevention of postERCP pancreatitis. Gut. 2008; 57: 1262-1267.

16. Li L, Han Z, Yuan H, Zhang G, Jia Y, He C. Nonsteroidal anti-inflammatory drugs reduce the incidence of post-endoscopic retrograde cholangiopancreatography pancreatitis: A meta-analysis. J Hepatobiliary Pancreat Sci. 2017; 24: 520-529.

17. Alizadeh M, Abbasinazari M, Hatami B, Abdi S, Ahmadpour F, Dabir $S$, et al. Comparison of rectal indomethacin, diclofenac and naproxen for the prevention of post-endoscopic retrograde cholangiopancreatography pancreatitis. European Journal of Gastroenterology \& Hepatology. 2017; 29: 349-354.

18. Funatsu E, Masuda A, Takenaka M, Nakagawa T, Shiomi H, Yoshinaka $\mathrm{H}$, et al. History of post-endoscopic retrograde cholangiopancreatography pancreatitis and acute pancreatitis as risk factors for post-ERCP pancreatitis. Kobe J Med Sci. 2017; 63: E1E8.

19. Testoni PA, Mariani A, Giussani A, Vailati C, Masci E, Macarri G, et al. Risk factors for post-ERCP pancreatitis in high- and low- volume centers and among expert and non-expert operators: a propective multicentre study. Am J Gastroenterol. 2010; 105: $1753-1761$.

20. Bailey AA, Bourke MJ, Kaffes AJ, Byth K, Lee EY, Williams SJ. Needle-knife sphincterotomy: Factors predicting its use and the relationship with post-ERCP pancreatitis. Gastrointestinal Endoscopy. 2010; 71: 266-271.

21. Tse F, Yuan Y, Moayyedi P, Leontiadis GI. Guide wire-assisted cannulation for the prevention of post-ERCP pancreatitis: A systematic review and meta-analysis. Endoscopy. 2013; 45: 605-618.

22. Artifon EL, Sakai P, Cunha JE, Halwan B, Ishioka S, Kumar A. Guidewire cannulation reduces risk of post-ERCP pancreatitis and facilitates bile duct cannulation. Am J Gastroenterol. 2007; 102: 2147-2153.

23. Ang TL, Kwek AB, Song M, Li JW, Thurairajah PH. Comparative study of strategies for preventing post-ERCP pancreatitis after early precut sphincterotomy for biliary access. J Dig Dis. 2016; 17: 692-696.

24. Cennamo V, Fuccio L, Zagari RM, Eusebi LH, Ceroni L, Laterza L, et al. Can early precut implementation reduce endoscopic retrograde cholangiopancreatigraphy-related complication risk? Meta-analysis of randomised controlled trials. Endoscopy. 2010; 42: 381-388.

25. Gong B, Hao L, Bie L, Sun B, Wang M. Does precut technique improve selective bile duct cannulation or increase post-ERCP pancreatitis rate? A meta-analysis of randomised controlled trials. Surg Endosc. 2010; 24: 2670-2680.

26. Choudhary A, Bechtold MIL, Arif M, Szary NM, Puli SR, Othman $\mathrm{MO}$, et al. Pancreatic stents for prophylaxis against post-ERCP pancreatitis: a meta-analysis and systematic review. Gastrointest Endosc. 2011; 73: 275-282.

27. Mazaki T, Mado K, Masuda H, Shiono M. Prophylactic pancreatic stent placement and post-ERCP pancreatitis: an updated metaanalysis. J Gastroenterol. 2014; 49: 343-355.

28. Singh P, Das A, Isenberg G, Wong RC, Sivak MV Jr, Agrawal D, et al. Does prophylactic pancreatic stent placement reduce the risk of post-ERCP acute pancreatitis? A meta-analysis of controlled trials. Gastrointest Endosc. 2004; 60: 544-550.

29. Pancreatic stent placement for prevention of post-ERCP pancreatitis: a cost-effectiveness analysis. Gastrointest Endosc. 2007; 65: 960-968.

30. Yoo YW, Cha SW, Lee WC, Kim SH, Kim A, Cho YD. Double guide wire technique vs trans-pancreatic precut sphincterotomy in difficult biliary cannulation. World J Gastroenterol. 2013; 19: 108114.

31. Dumonceau JM, Andriulli A, Elmunzer BJ, Mariani A, Meister T, Deviere J, et al. Prophylaxis of post-ERCP pancreatitis: European Society of Gastrointestinal Endoscopy (ESGE) guideline - updated June 2014. Endoscopy. 2014; 46: 799-815.

32. Saad AM, Fogel EL, McHenry L, Watkins JL, Sherman S, LazzellPannell $L$, et al. Pancreatic duct stent placement prevents postERCP pancreatitis in patients with suspected sphincter of Oddi dysfunction but normal manometry results. Gastrointestinal Endoscopy. 2008; 67: 255-261.

33. Ito K, Fujita N, Kanno A, Matsubayashi H, Okaniwa S, Nakahara $\mathrm{K}$, et al. Risk factors for post-ERCP pancreatitis in high-risk patients who have undergone prophylactic pancreatic duct stenting: a multicentre retrospective study. Intern Med. 2011; 50: 2927-2932.

34. Choksi NS, Fogel, Cote GA, Romagnuolo J, Elta GH, Scheiman JM, 
et al. The risk of post-ERCP pancreatitis and the protective effect of rectal indomethacin in cases of attempted but unsuccessful prophylactic pancreatic stent placement. Gastrointestinal Endoscopy. 2015; 81: 150-155.

35. Akbar A, Abu Dayyeh BK, Baron TH, Wang Z, Altayar O, Murad $\mathrm{MH}$. Rectal nonsteroidal anti-inflammatory drugs are superior to pancreatic duct stents in preventing after endoscopic retrograde cholangiopancreatography: A network meta-analysis. Clin Gastroenterol Hepatol. 2013; 11: 778-783.

36. Elmunzer BJ, Higgins PDR, Saimi SD, Scheiman JM, Parker RA, Chak $A$, et al. Does rectal indomethacin eliminate the need for prophylactic pancreatic stent placement in patients undergoing high-risk ERCP? Post-hoc efficiency and cost-benefit analyses using prospective clinical trial data. Am J Gastroenterol. 2013; 108: 410-415.

37. Lee TH, Moon JH, Choi HJ, Han SH, Cheon YK, Cho YD, et al. Prophylactic temporary $3 \mathrm{~F}$ pancreatic duct stent to prevent postERCP pancreatitis in patients with difficult biliary cannulation: A multicentre, prospective, randomised study. Gastrointestinal Endoscopy. 2012; 76: 578-585.

38. Freeman ML. Use of prophylactic pancreatic stents for the prevention of post-ERCP pancreatitis. Gastroenterol Hepatol. 2015 11: 420-422.
39. Smeets XJNM, Da Costa DVW, Besselink MG, Bruno MJ, Fockens $\mathrm{P}$, Mulder $\mathrm{CJ}$, et al. Systematic review: periprocedural hydration in the prevention of post-ERCP pancreatitis. Alimentary pharmacology and therapeutics. 2016; 44: 541-553.

40. Buxbaum J, Yan A, Yeh K, Lane C, Nguyen N, Laine L. Aggressive hydration with lactated Ringer's solution reduces pancreatitis following endoscopic retrograde cholangiopancreatography. Clin Gastroenterol Hepatol. 2014; 12: 303-307.

41. Park $\mathrm{CH}$, Paik WH, Park ET, Shim CS, Lee TY, Kang C, et al. Aggressive intravenous hydration with lactated Ringer's solution for prevention of post-ERCP pancreatitis: A prospective, randomised, multicentre clinical trial. Endoscopy. 2018; 50: 378385. 